\title{
Un canto a tres voces. Reseña de Álvarez Bravo, P. (2016). Memoria Visual de Legua Emergencia, vida y oficio de Mario Alarcón. Santiago de Chile: Ediciones Cenfoto-UDP, 120 pp. ISBN: 978-956-8137-08-3
}

Pedro Pablo Achondo Moya

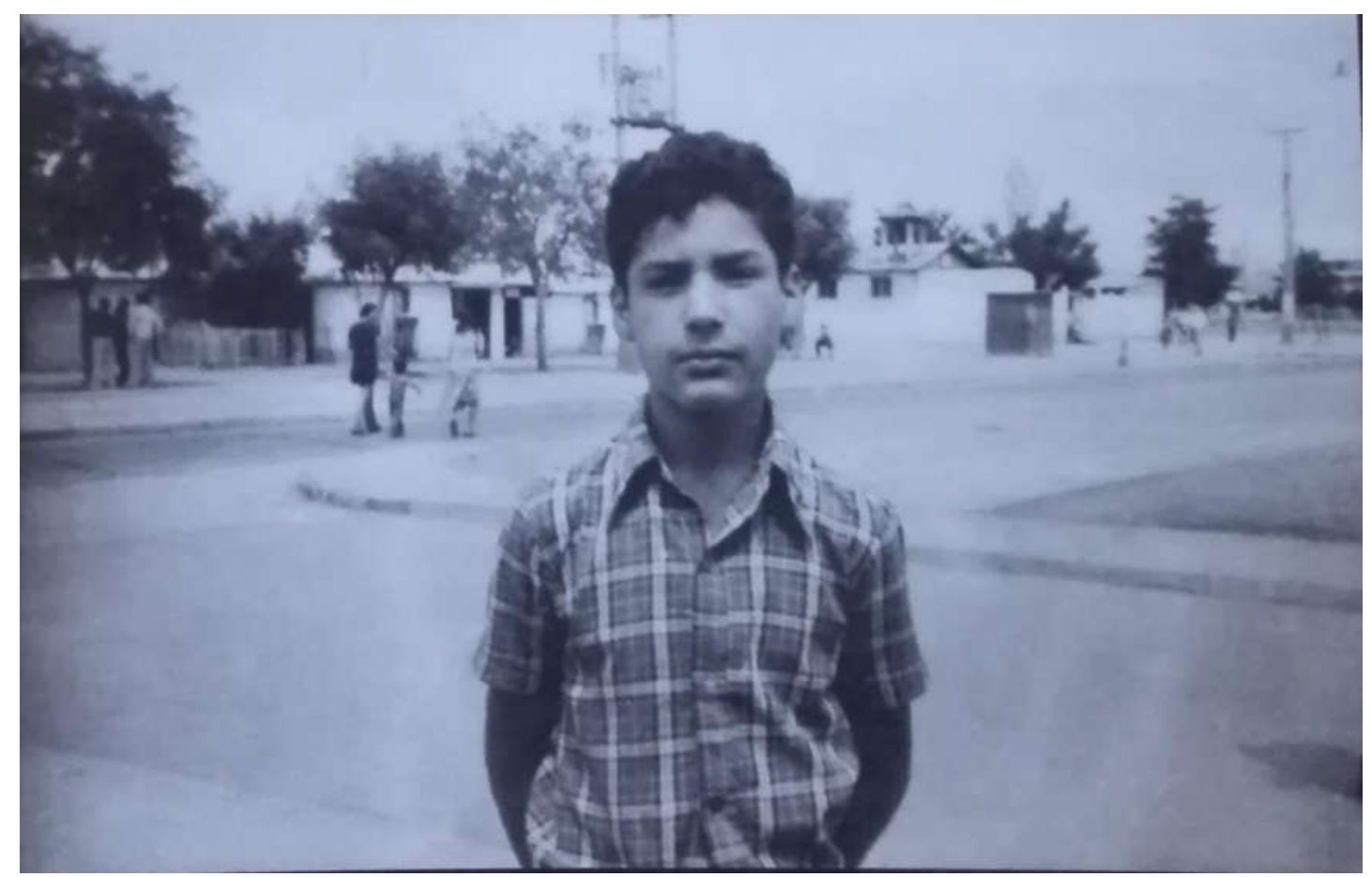

Nos enfrentamos a un hermoso canto a tres voces, tres voces que se entrelazan en este trabajo serio, artístico y político sobre la memoria. El autor mira al protagonista, Paulo mira a Mario y juntos miran Legua Emergencia. Mientras ambos amigos y vecinos la habitan, la sufren, la sueñan. La Legua y Juegos Infantiles, pequeña calle de la población, pequeño espacio en donde transcurre un tiempo precioso para quienes se conversan sin más. Allí en ese espacio Mario y Paulo realizan el urgente ejercicio de la memoria. Repasan juntos la Recibido: 23-10-17. Aceptado: 13-12-17.

Pedro Pablo Achondo es Licenciado en filosofía y Magíster en teología, Centre Sèvres, París. Francia.

Contacto: P. P. Achondo, C/ Faustino Sarmiento 275 Ñuñoa.

pedropablosscc@gmail.com

Cómo citar: Achondo, P. (2016). Un canto a tres voces. Reseña de Álvarez Bravo, P. (2016). Memoria Visual de Legua Emergencia, vida y oficio de Mario Alarcón. Santiago de Chile: Ediciones CenfotoUDP, 120 pp. Revista Stultifera, 1 (1), 113-118. ISSN 0719-983X

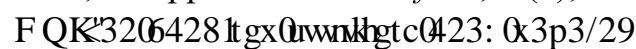




\section{RESEÑA DE ÁLVAREZ BRAVO, P. (2016)}

historia de uno que suscita las historias del otro. Paulo quiere mirar por el lente de Mario, Mario abre sus negativos y juntos redescubren la emergencia en que La Legua ha vivido y sigue viviendo.

El ejercicio de memoria visual que el autor nos regala ha suscitado en mí algunas consideraciones sobre la memoria, su vitalidad y urgencia. Y lo hace desde mi propio oficio como teólogo y filósofo. Es un libro que dice mucho, que afirma la fuerza de los detalles y en cómo ahí se nos juega la vida, de qué manera los pobres viven y sobre viven en la inestabilidad de todo, como si el suelo familiar, habitacional, educacional, de la salud, los sueños y las verdaderas posibilidades estuvieran siempre coqueteando entre el quedarse y el perderse, entre el afirmarse y el ser arrebatado. Vida y oficio de Mario Alarcón es un libro en claroscuro, como su vida misma, como las casitas de Legua Emergencia. Allí hay luz y color- que expone también nuestras oscuridades, sombras, contradicciones, luchas y fracasos. Son nuestras transgresiones las que serán salvadas, decía el teólogo brasilero Nilo Ribeiro Junior. Es nuestra oscuridad la que será transfigurada, haciéndose luz, manifestación, fainos. Más que fotografías, Mario nos regala una Leguafanía, una nueva muestra de eso que no se ve. De eso que ha dejado de ser, de eso que no se deja ver y, desde mi punto de vista uno de los méritos de la memoria, de aquello que nunca llegó a ser.

La infancia en el libro es fundamental; son los niños los dueños de la calle. Son los niños descalzos, los niños del vecino, los niños sin padres, los niños y niñas que no saben que la vida no es solo así y no tiene porqué serlo. Esa pregunta vendrá después y a más de alguno la dictadura cívico-militar le habría arrebatado la respuesta. Dice el autor que los niños no cabían en Emergencia (Álvarez, 2016). Familias numerosas en donde los niños entraban y salían, comían en diversas mesas y dormían en camas prestadas junto a otros. Esos niños, pese y contra todo, mantenían viva una esperanza común, una alegría compartida que décadas después el narcotráfico y la intervención policial han ensombrecido, como para ahuyentar las dudas respecto a ese claroscuro de la cotidianidad legüina. Al decir de Gabriel Salazar, en su bello artículo después convertido en texto, Ser niño huacho en la historia de Chile, son los niños los que también hacen historia (Salazar, 2007).

¿Qué hizo distinta la vida de Mario? A sabiendas de que cada vida es única y, desde ella, hermosa; en Mario aparece algo que lo tiñe todo: su oficio, y como dice el subtítulo, 


\section{PEDRO PABLO ACHONDO MOYA}

inseparable de su vida. La fotografía y su lente: Iris. Su vida y su arte, su amor, la compañera de sus días y la otra compañera, esa cámara por la cual Mario fue haciéndose de la realidad, apropiándosela y transformándola en ese cuarto oscuro en donde todo desaparecía y volvía a aparecer de otro modo. Quizá como cualquiera que hace de su oficio la vida, - una hermosa confusión inseparable; no es extraño encontrar en la vida de fotógrafos, muchos de ellos grandes artistas, esa apropiación: Jorge Larraín en Chile, Manuel Álvarez Bravo en México o Sebastián Salgado en Brasil, para no salirse del contexto latinoamericano. Mario sin mayores reconocimientos encontró un arte y lo hizo realización, pasión, trabajo, oficio. Tal vez, todos debiéramos encontrar eso que llamamos vocación. Aquello por lo que la vida se llena de sentido y permite sobrepasar escollos, penurias, miserias. Aquello que detiene el tiempo. Pues la memoria y el arte se entrecruzan suscitando aquello que no llegó a ser en el presente, pero que la vida nos impulsa a darle una segunda oportunidad. Si la memoria busca traer aquello arrebatado por la historia, el arte se torna una de las plataformas para que tome cuerpo, espacio y presente, voz y latido, rostro y conquista.

Paulo Álvarez afirma que el enemigo de la memoria no es el olvido, sino la memoria despolitizada, instrumentalizada, manoseada, hipócritamente construida (Álvarez, 2016, p. 32). Y tiene toda la razón. Valdría agregar, como dice un historiador de la memoria judía, Josef Yerushalmi, que lo contrario de la memoria es la injusticia, pues recordar es un acto de justicia (Yerushalmi, 1988). Olvidar es un acto de injusticia respecto al mal y los sufrimientos en la historia de los pueblos y en las historias personales, como la de Mario e historias colectivas, como las de Legua Emergencia. Una sociedad del olvido corresponde a una construcción injusta que no toma en cuenta, suficientemente, el mal y la negatividad del mundo ni la muerte de inocentes, ni el sufrimiento siempre terrible de las víctimas de la historia. La fotografía de Mario, en Legua Emergencia y el libro - una segunda fotografía y un trabajo de memoria, de Paulo Álvarez, constituye, en este sentido; un acto de justicia; una búsqueda por hacer justicia a un grupo humano marginalizado, empobrecido, violentado y atemorizado. Un esfuerzo por contribuir en aquella lucha llamada justicia. Y todo ello, desde la vida sencilla de un fotógrafo de población marginal. 


\section{RESEÑA DE ÁLVAREZ BRAVO, P. (2016)}

Así, la memoria es una manera de comprender la realidad doliente, una hermenéutica que nos permite hacer visible aquello que de otra forma permanecería invisible. Sin un adecuado trabajo de la memoria de las injusticias no habrá justicia posible ${ }^{1}$.

Nuestras sociedades numéricas y del olvido, sin narrativas, sin testimonios; pierden la riqueza de una vida vivida y sufrida en la carne concreta del narrador. Dicho de otro modo, sin la memoria, tanto la sociedad, como la política y la religión; no alcanzan a vislumbrar, percibir, dejarse tocar y transformar por lo más propio de la vida humana. Allí radica la fuerza del testimonio, en cuanto ejercicio de memoria de una vida padecida. Hacer memoria del sufrimiento, del dolor, de las injusticias es siempre un peligro para el orden establecido, la memoria es peligrosa, en el decir del teólogo alemán Metz, pues cuestiona los cimientos de instituciones, relaciones, maneras, leyes y prácticas normalizadas que continúan reproduciendo injusticias y seres humanos-desechos, arrojados a las periferias sin importarle mucho a nadie.

Metz (2007) lee la bienaventuranza felices los que lloran (Mateo 5, 5) desde la perspectiva del deber de memoria: aquellos que lloran son los que hacen memoria de los desaparecidos, son los que no olvidan a los ausentes y sufrientes. Así, establece una hermosa y profunda aproximación entre el deber de memoria, la compasión y el don de lágrimas. Cuántas fotografías de Mario habrán provocado en él un llanto.

Vida y oficio es un testimonio visual, que a contracorriente de la pornografía y del voyerismo fotográfico actual, suscita en nosotros memorias. Todos somos un cúmulo de memorias; cada individuo posee una multiplicidad de memorias (colectivas e individuales, pretéritas y recientes, adquiridas y vivenciadas), las que se superponen y oponen entre ellas. Estas memorias se constituyen en trazos inscritos en lo íntimo de la persona. Se trata de memorias que poseen una dimensión pública en la medida en que condicionan y conforman el imaginario común de la sociedad contemporánea. De alguna manera, somos lo que recordamos. Y también lo que no queremos recordar.

En una nota al pie (n3), Álvarez (2016) dice: "la pobreza nunca ha escandalizado demasiado, a no ser como fetiche" (p. 10), haciendo alusión a fotografías de Sergio Larraín de niños en condición de calle que el padre Hurtado atendía. Nuestro país se ha construido 


\section{PEDRO PABLO ACHONDO MOYA}

de esa forma: sin escandalizarse demasiado por la pobreza; pobreza que según Herman Cohen, filósofo alemán de fines del siglo XIX, principios del XX, es el verdadero mal de la humanidad.

El verdadero problema del mal es el sufrimiento que causa el hombre (...) Los profetas y los salmos tienen el convencimiento social de que la pobreza representa el mayor sufrimiento del género humano (...) que la pobreza y no la muerte constituyen el auténtico enigma de la vida humana. (Reyes-Mate, 1997, p. 232)

Una sociedad que ha crecido de espaldas a los pobres, silenciando su pobreza, transformándola en marketing solidario y generando pobretólogos de clase alta, es una sociedad hipócrita, inconsciente de su propio mal y con muy pocas posibilidades de revertirlo. Legua Emergencia y muchos otros rincones claroscuros de nuestras tierras; urbanos y campesinos, de montaña y de costa; viven la extrema precariedad sin ninguna posibilidad de transformar su destino ni el de sus hijos.

Mientras escribo estas líneas y pienso en la suerte de Mario Alarcón, me llegan mensajes del Pipe, amigo que hace un par de meses salió de la cárcel de Río Bueno para volver a algo como una vida en Concepción. Una vida angustiada por la imposible inserción en la sociedad, sin trabajo, sin dinero, apaliado por una golpiza, intentando rescatar a su hijo arrebatado por el Sename. Pipe solo se saca selfies junto a su hijito mayor acostado en la cama del cuarto que con su compañera arriendan y deben hace meses. Sus fotos son en colores y filtradas para resaltar los colores que no encuentra en ningún lugar de su vida. El Pipe vive esa doble o triple pobreza de hoy, esa que ni para fetiche alcanza. La pobreza debe no solo escandalizarnos, sino dolernos, asquearnos. Si no nos brota un sentimiento encarnado de compasión ante la vida del Pipe, las fotos de Mario y el libro de Paulo Álvarez habrán sido en vano.

El texto, memoria-fotografía de Legua Emergencia narrado desde el poblador y fotógrafo Mario Alarcón tiene a Iris Rivas Rivas como musa. Solo el lector podrá dar cuenta de su poderoso significado. El significado de la palabra Iris es aquella que viene a anunciar. En lo que concierne al ojo, el iris tiene la función de controlar la cantidad de luz que penetra en él. El iris de Mario fue su compañera, que le enseñó de cuidado y compasión, de esfuerzo 
y entrega, ella es el corazón de Mario y la vida de hombres y mujeres como ellos el corazón de esta memoria.

\section{Notas}

${ }^{1}$ Yerushalmi, Y. (1988). Réflexions sur 1'oubli. En AAVV. Usages de l'oubli. Colloque de Royaumont. Paris : Seuil.Ver también la interesante obra de Yerushalmi, Y. (2002). Zajor: La Historia Judía y la Memoria Judía. Bercelona: Anthropos.

\section{Referencias}

Álvarez, P. (2016). Memoria Visual de Legua Emergencia, vida y oficio de Mario Alarcón. Santiago, Chile: Ediciones Cenfoto-UDP

Metz, J. (2007). Memoria Passionis. Una evocación provocadora en una sociedad pluralista. Santander, España: Sal Terrae.

Reyes-Mate, M. (1997). Memoria de occidente. Barcelona, España: Anthropos.

Salazar, G. (2007). Ser niño "huacho" en la historia de Chile (siglo XIX). Santiago, Chile: LOM Ediciones.

Yerushalmi, Y. (1988). Réflexions sur l'oubli. En Usages de l'oubli (pp. 7-22). Paris: Le Seuil (programme ReLIRE). 


\section{REVISTA STVLTIFERA DE HUMANIDADES Y CIENCIAS SOCIALES}

VOLUMEN 1, NÚMERO 1, PRIMER SEMESTRE DEL 2018

ISSN 0719-983X

\section{Artículos de Humanidades y Ciencias Sociales}

La violencia como espectáculo.

Juan Carlos Pérez Jiménez

El amo castrado.

Elisa Freijo Corbeira

España, una meditación política: Cataluña y Euskadi.

Mikel Aramburu Zudaire

Del saber sabio al saber dramatizado. Nuevos fundamentos para la aplicación permanente del teatro en el aula.

Luis Fernando Lara Coronado

Ontotecnia, ingeniería organizacional y actores emergentes.

Alejandro Ochoa Arias y Juan Antonio González de Requena Farré

\section{Reseñas}

Memoria Visual de Legua Emergencia, vida y oficio de Mario Alarcón.

Pedro Pablo Achondo Moya

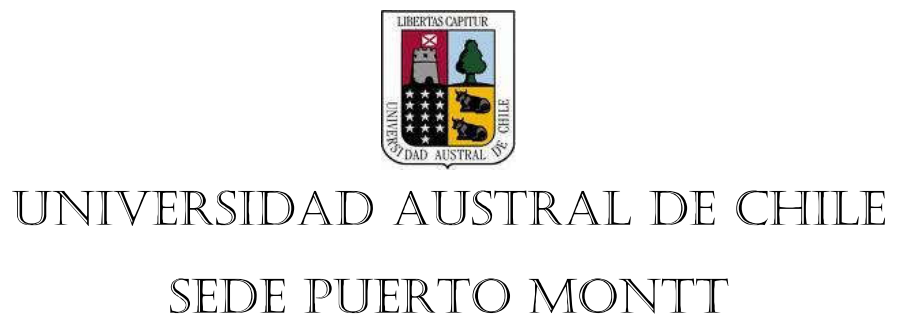

